Article

\title{
Efficient Recovery of Silver from Crystalline Silicon Solar Cells by Controlling the Viscosity of Electrolyte Solvent in an Electrochemical Process
}

\author{
Jun-Kyu Lee ${ }^{1}$, Jin-Seok Lee ${ }^{1, * \mathbb{D}}$, Young-Soo Ahn ${ }^{1}$ and Gi-Hwan Kang ${ }^{2}$ \\ 1 Separation and Conversion Materials Laboratory, Korea Institute of Energy Research, Daejeon 305-343, \\ Korea; jklee3474@kier.re.kr (J.-K.L.); ysahn@kier.re.kr (Y.-S.A.) \\ 2 Photovoltaic Laboratory, Korea Institute of Energy Research, Daejeon 305-343, Korea; ghkang@kier.re.kr \\ * Correspondence: jslee@kier.re.kr; Tel.: +82-42-860-3745; Fax: +82-42-860-3133
}

Received: 30 September 2018; Accepted: 29 October 2018; Published: 2 November 2018

check for updates

Featured Application: We present an electrochemical method for metal recovery by using an organic acid solution as an electrolyte, and provided the method to reduce the viscosity of electrolyte, which can enhance the mobility of metal ions.

\begin{abstract}
We present electrowinning of silver (Ag) from crystalline silicon (c-Si) solar cells using a solution of methanesulfonic acid (MSA) as the electrolyte. Ag dissolved effectively in MSA because of its high solubility in MSA; however, the electrochemical recovery of Ag from MSA solutions was found to be inefficient because of the low mobility of Ag ions in MSA, owing to its high viscosity. Therefore, we decreased the viscosity of MSA by adding deionized (DI) water, as a possible method for enhancing the mobility of Ag ions. The concentrations of added DI water were 0, 1.1, 5.0, 9.3, and $20.8 \mathrm{M}$, respectively. Further, we performed cyclic voltammetry for each solution to calculate the diffusion coefficient using the Randles-Sevcik equation, and analyzed the viscosity of MSA solutions depending on the concentration of added water using a rheometer. The morphologies of the electrochemically recovered $\mathrm{Ag}$ particles changed with variations in the amount of the added water, from branch-like structures to dendritic structures with a decreasing size. Moreover, the cathodic current efficiency increased considerably with increasing concentration of the added DI water. Finally, we recovered $\mathrm{Ag}$ with $>99.9 \%$ (3N) purity from c-Si solar cells by electrowinning, as determined by glow discharge mass spectrometry.
\end{abstract}

Keywords: crystalline silicon solar cell; electrowinning; silver; ion mobility; cathodic efficiency; morphology

\section{Introduction}

Demand for photovoltaic (PV) systems, that have been installed since the 1990s, has grown exponentially [1]. Hence, a significant number of end-of-life (EoL) modules are expected to be generated, and this number is growing exponentially because the lifetime of a PV module is approximately 20-30 years [2]. Therefore, PV modules have been included in the European Waste Electrical and Electronic Equipment (WEEE) directive for electronic waste in 2012 [3], as well as in the domestic laws of European countries. According to the WEEE directive, the annual collection target is $65 \%$ (by mass) of all equipment in the market, or $85 \%$ of waste generated starting from 2018 . The recovery target is $85 \%$, and recycling is $80 \%$ over the same period [4]. Among the PV module components, silver (Ag), which is used as a front electrode of a solar cell, is one of the precious materials. From the standpoint of value, $\mathrm{Ag}$ is by far the most expensive component per unit mass of a c-Si panel, followed by copper, silicon, aluminum, glass, and polymer [5]. Therefore, recovery of Ag 
from EoL PV modules is beneficial from the economic perspective. For this reason, some researchers have reported on the recovery of $\mathrm{Ag}$ from c-Si solar cells [6-12].

Generally, dissolution of $\mathrm{Ag}$ is the most effective method because Ag is relatively dispersed throughout the solar cell. Ag can be recovered either through electrolysis or through precipitation when dissolved in a leaching solution, as well as by using a metal replacement method [13]. Another method for recovering Ag is its extraction using a cyanide solution [14] or nitric acid [15]. However, these methods can cause further environmental problems, such as the generation of waste acid solutions and toxic fumes. Yang et al. reported [16] an environmentally friendly method for recovering $\mathrm{Ag}$ from EoL solar cells using methanesulfonic acid (MSA) containing an oxidizing agent because MSA has many advantages, such as a high saturation metal salt solubility, high conductivity, relatively low toxicity, and the simplicity of the effluent treatment method [17]. However, this method requires more than two steps because of the pretreatment processes, which involve dissolution, precipitation, and reduction. In addition, the purity of the recovered Ag is relatively low, thus necessitating an additional electrorefining step to produce high-purity Ag.

In the present study, we therefore utilized an electrowinning process that is environmentally friendly, using a high-solubility MSA solution. The viscosity of the MSA solution with the oxidizing agent is the most important parameter when attempting to efficiently recover Ag from a c-Si solar cell by the electrowinning process, as this directly affects the cathode efficiency and morphology of the recovered Ag. To maximize the efficiency of the electrochemical process, several parameters, such as the viscosity of MSA and the concentration of the added water, were varied to find the optimal condition, which was subsequently applied to the electrowinning process using an MSA solution with dissolved Ag.

\section{Materials and Methods}

\subsection{Dissolution of Ag in an Organic Solvent}

Ag powders (3N, Sigma-Aldrich, Saint Louis, MO, USA) were used to determine the optimal conditions for the electrochemical recovery process for Ag via a series of steps. First, Ag powders were immersed in a mixed solution of MSA (99 wt \%) with $\mathrm{H}_{2} \mathrm{O}_{2}(30 \mathrm{wt} \%)$ for $1 \mathrm{~h}$ at room temperature (mixing ratio of MSA and $\mathrm{H}_{2} \mathrm{O}_{2}$ is 90:10 (vol \%)), which was then stirred for $1 \mathrm{~h}$ at $200 \mathrm{rpm}$. As shown in Table 1, different concentrations of water were added to the mixed solution of MSA and $\mathrm{H}_{2} \mathrm{O}_{2}(0,1.1$, 5.0, 9.3, and 20.8 M), which are, hereafter, referred to as (a), (b), (c), (d), and (e), respectively. A PGSTAT 302N Autolab system (Eco Chemie, Utrecht, Netherlands) was used for cyclic voltammetry (CV) of the Ag-dissolved organic solution, depending on the various amounts of water added at scan rates of $50,100,150,200,250$, and $300 \mathrm{mV} \mathrm{s}^{-1}$. A platinum (Pt) wire and a tungsten $(\mathrm{W})$ plate were used as the working electrode and counter electrode, respectively. A HAAKE MARS III rheometer (Thermo Scientific, Waltham, MA, USA) was used to analyze the viscosity of the Ag-dissolved solution.

Table 1. Experimental conditions of the electrowinning process.

\begin{tabular}{|c|c|c|c|c|c|}
\hline Contents & (a) & (b) & (c) & (d) & (e) \\
\hline Concentration of added water (M) & 0 & 1.1 & 5.0 & 9.3 & 20.8 \\
\hline MSA/oxidizing agent & \multicolumn{5}{|c|}{$9: 1$} \\
\hline Concentration of silver $(\mathrm{M})$ & \multicolumn{5}{|c|}{$5.56 \times 10^{-5}$} \\
\hline Cathode & \multicolumn{5}{|c|}{ Tungsten plate } \\
\hline Anode & \multicolumn{5}{|c|}{ Platinum wire } \\
\hline
\end{tabular}

\subsection{Recovery of Ag by Electrowinning}

The optimal amount of the added water was applied to ten 6" solar cells to demonstrate the recovery of Ag using an electrowinning system. During the electrowinning process, conducted using a PGSTAT 302N Autolab system (Eco Chemie, Utrecht, Netherlands), a Pt wire was used as the anode, 
and a W plate was used as the cathode. Current was applied to the system using a MSA and $\mathrm{H}_{2} \mathrm{O}_{2}$ mixed solution as the electrolyte, and a $\mathrm{Ag} / \mathrm{AgCl}(3 \mathrm{M} \mathrm{KCl})$ reference electrode. A $3.9 \mathrm{~cm}^{2}$ area of the cathode was exposed to the electrolyte solution, which was maintained at room temperature during electrowinning at a current density of $76.9 \mathrm{~mA} \mathrm{~cm}^{-2}$.

The morphology of the electrodeposited Ag was analyzed using a scanning electron microscope (SEM; Hitachi S-4700, Tokyo, Japan). An X-ray diffractometer (XRD; Rigaku DMAX-2500, Tokyo, Japan) was employed to investigate the phases of the recovered Ag. The concentrations of various impurities in the Ag materials were determined using a glow discharge mass spectrometer (GDMS; Thermo Scientific VG 9000, Waltham, MA, USA).

\section{Results and Discussion}

Although Ag has excellent solubility in MSA, the electrochemical efficiency of MSA is not expected to be good, owing to its high viscosity, because the Ag ions have lower mobility in a high-viscosity electrolyte [18], which is also related to diffusion $[19,20]$. Therefore, CV was performed to confirm the diffusion coefficient according to the amount of water added to MSA and the CV curves are shown in Figure 1. The oxidation and reduction peaks tend to increase with increasing scanning speed in all the CV curves. In addition, as the concentration of the added water increased, the switching point rose to the upper side of the graph. In other words, the larger the concentration of the added water, the greater is the electrochemical behavior of the reversible electrode reaction. This means that the oxidation-reduction reaction of the material is fast enough to maintain the concentrations of the reactants and products on the electrode surface in equilibrium with the changes in voltage. When the concentration of the added water is small, the switching point drops to the bottom of the graph because the rate of diffusion of the material to the electrode surface is slow, and does not follow the rate of the oxidation-reduction reaction. To confirm the relationship between the concentration of the added water and the diffusion rate, the Randles-Sevcik equation was used to calculate the diffusion coefficient of the electrolyte according to the concentration of the added water. In general, the peak current of a diffusion-controlled reversible or quasi-reversible electrochemical reaction follows the Randles-Sevcik equation [21]:

$$
i_{p}=0.4463 n F \sqrt{\frac{n F D}{R T}} A C \sqrt{v},
$$

where $i_{p}$ is the peak current, $n$ is the number of electrons, $F$ is the Faraday constant, $T$ is the temperature in Kelvin, $R$ is the gas constant, $A$ is the surface area of the working electrode, $D$ is the diffusion coefficient of the electroactive species, $C$ is the bulk concentration of the electroactive species, and $v$ is the scan rate employed in the CV measurements. Thus, the diffusion coefficients for the MSA solution at $298 \mathrm{~K}$ are calculated from the slope of the plot of $i_{p}$ versus $\sqrt{v}$, and the diffusion coefficients of $\mathrm{Ag}$ ions, as shown in Figure 2. As shown, the diffusion coefficient of the electrolyte solution increases with the addition of water. That is, the addition of water to the MSA electrolyte solution increases the degree of diffusion, which implies that the viscosity is controlled by the addition of water. The Stokes-Einstein equation can be given by the following generalized expression [22]:

$$
D=k T / 6 \pi \eta r,
$$

where $D$ is the diffusion coefficient, $\eta$ is the viscosity of solvent, and $r$ is the radius of the diffusing particle. It can be seen from this equation that the diffusion coefficient and viscosity are inversely proportional. 

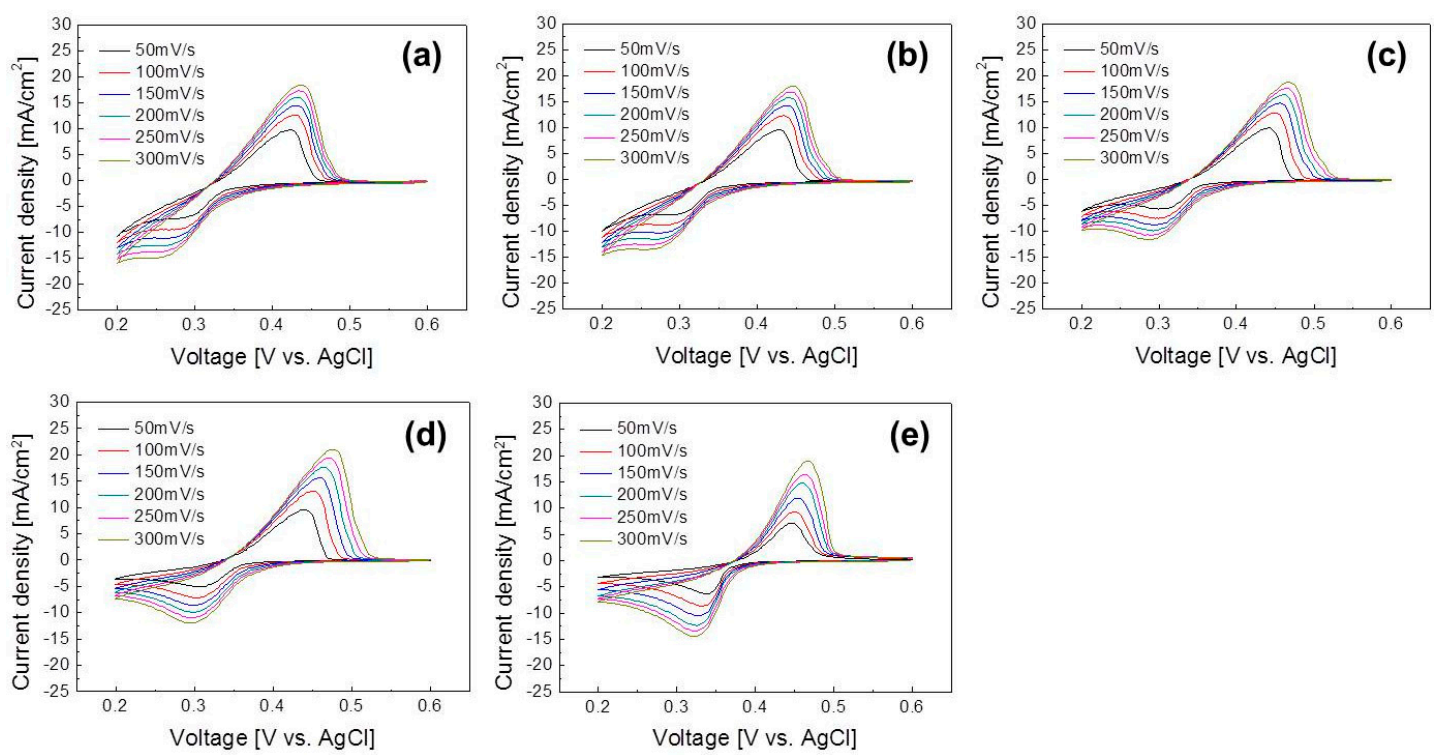

Figure 1. Cyclic voltammetry curves depending on the concentration of the added water: (a) $0 \mathrm{M}$, (b) $1.1 \mathrm{M}$, (c) $5.0 \mathrm{M}$, (d) $9.3 \mathrm{M}$, and (e) $20.8 \mathrm{M}$.

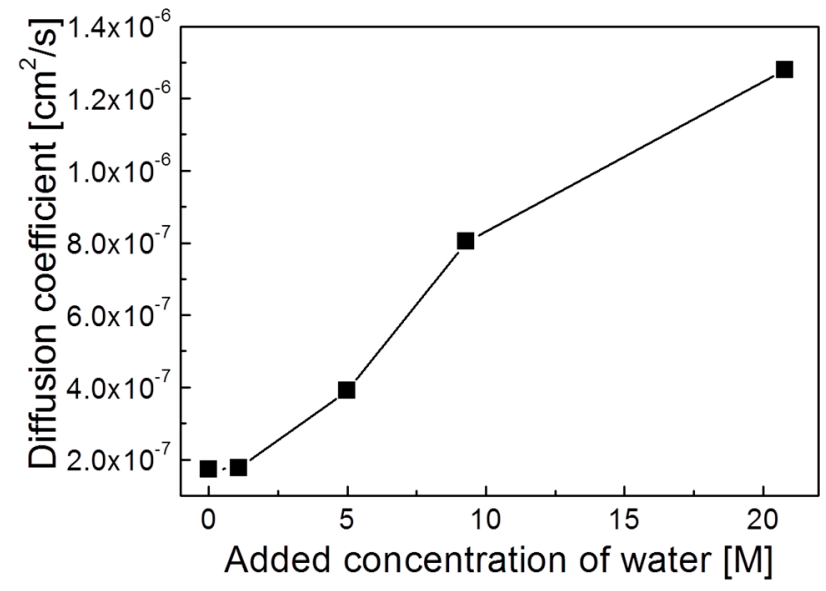

Figure 2. Diffusion coefficient depending on the concentration of the added water.

As shown in Figure 2, therefore, the diffusion coefficient increases with a decrease in the viscosity of the MSA solution. Even if the viscosity is controlled by adding water to the MSA solution, the solubility of the metal in the MSA solution is very high [23]; thus, the ion diffusion in the electrolyte can be controlled by adding water to the MSA solution. The viscosity of the MSA electrolyte was then measured to determine the actual viscosity according to the concentration of the added water, and the results are shown in Figure 3. In most cases, the viscosity was measured to be approximately $15 \mathrm{mPa} \cdot \mathrm{s}$, regardless of the experimental conditions. However, the measured viscosity tended to decrease sharply when the concentration of the added water was $20.8 \mathrm{M}$. This result is partially consistent with the diffusion coefficient calculated from the $\mathrm{CV}$ curve when the concentration of the added water was $20.8 \mathrm{M}$. Since the viscosity of MSA is too high, it is expected that the addition of $9.3 \mathrm{M}$ of water will not have a significant effect on the measured viscosity. However, when $20.8 \mathrm{M}$ of water was added, the viscosity of MSA was affected by the viscosity of water. For this reason, the viscosity is considered to decrease sharply. 


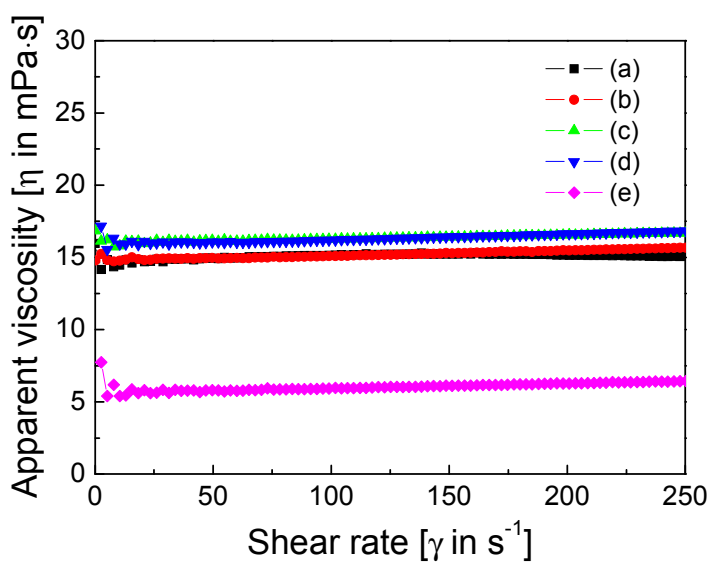

Figure 3. Variation in the viscosity of the MSA solution as a function of the concentration of added water: (a) 0 M, (b) $1.1 \mathrm{M}$, (c) $5.0 \mathrm{M}$, (d) $9.3 \mathrm{M}$, and (e) $20.8 \mathrm{M}$.

Figure 4 shows the large-scale cathodic and anodic potentiodynamic polarization curves recorded in the MSA electrolyte, according to the concentration of the added water for the recovery of Ag. The measured voltages in the cathodic and anodic branches tend to decrease due to an increase in the concentration of the added water. This trend could be associated with the change in the Ag ion mobility in the viscous electrolyte solution with the added water. The change in the cathodic and anodic branches indicates a reduction in the resistance during the electrochemical process. This phenomenon indicates the positive effect of adding water to the MSA electrolyte because of the increase in the cathodic efficiency. Figure 4 shows that the cathodic efficiencies improved under all experimental conditions. Particularly, the cathodic efficiency significantly improved when $20.8 \mathrm{M}$ of water was added. This phenomenon is attributed to the increased mass transport of Ag ions to the electrode surface, which is advantageous for improving the cathodic efficiency [24]. As mentioned above, this indicates that a lower viscosity facilitates Ag ion transport in the electrolyte. As the viscosity of the electrolyte decreases, the ion diffusion increases, and the cathode efficiency becomes higher.

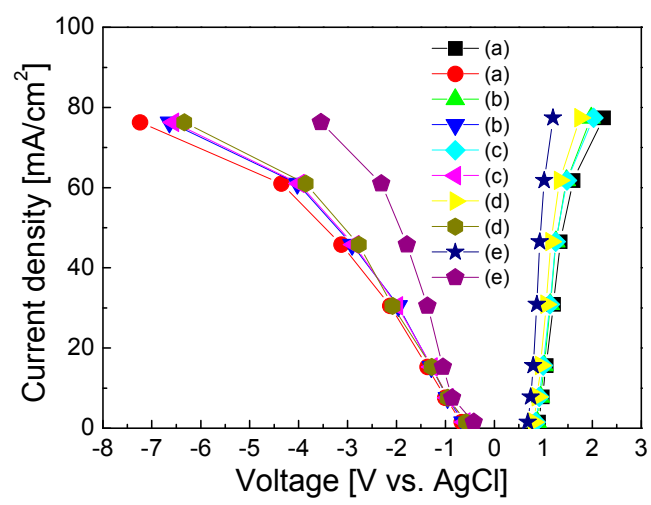

Figure 4. Dependence of the polarization curves on the concentration of the added water: (a) $0 \mathrm{M}$, (b) $1.1 \mathrm{M}$, (c) $5.0 \mathrm{M}$, (d) $9.3 \mathrm{M}$, and (e) $20.8 \mathrm{M}$.

Figure 5 shows the morphologies of the Ag deposits obtained at different concentrations of the added water in the electrowinning process. Branch-shaped electrodeposits were formed in the electrowinning process at an applied current density of $76.9 \mathrm{~mA} \mathrm{~cm}{ }^{-2}$. The size of the deposits decreased gradually with an increase in the concentration of the added water. In addition, the morphologies of the deposited Ag changed to a more dendritic shape. This phenomenon can be explained in terms of the ion mobility: with a decrease in the solution viscosity, the resistance of the solution to Ag ion mobility decreases; hence, the ion mobility and, consequently, acceleration of the rate of reaction, with the concentration of the added water, increases [25]. In general, structures with 
dendritic morphologies can grow in an electrolyte with a non-uniform ion concentration. Migration, diffusion, and convection affect the ion transport in an electrolyte [26]. As shown, the Ag ion concentration gradient in Figure $5 c$ is higher than those in Figure $5 a, b$ in an electric field because of the higher Ag ion mobility, which leads to dendritic growth. Therefore, the morphology of the deposited Ag changed to a more dendritic shape with an increase in the concentration of the added water, as predicted in Figure 5, due to an increase in the ion mobility. It is also observed that the decrease in the particle size is related to the concentration of the added water. The particle size of the deposited powder is dependent on the concentration of the electrolyte, and it was found to decrease with an increase in the electrolyte concentration [27]. Since the mobility of Ag ions increases as the concentration of the added water increases, it is expected to have the same effect as that of a high Ag concentration.
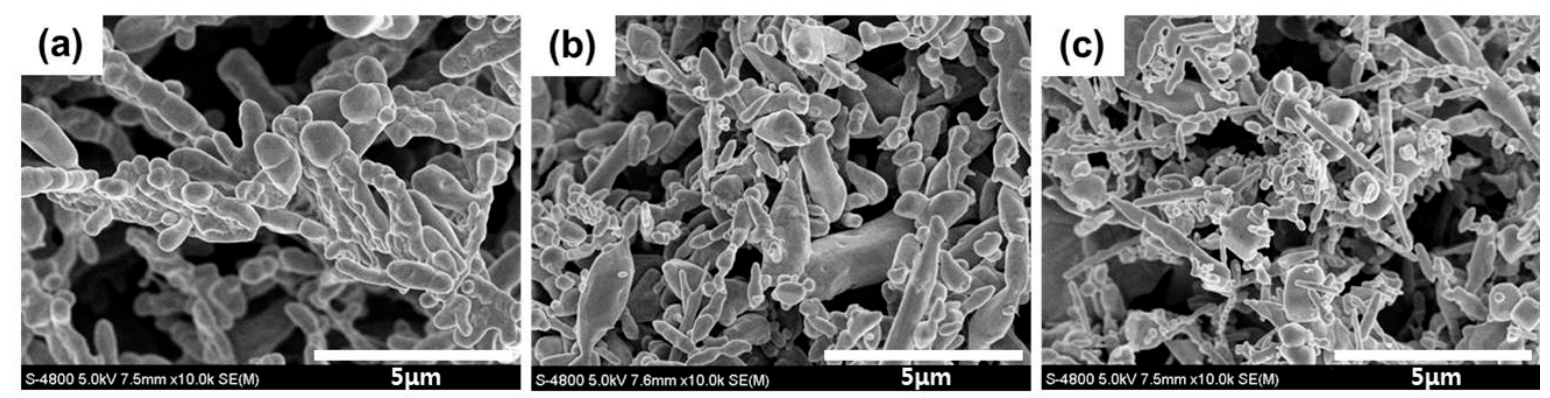

Figure 5. Microstructures of recovered Ag according to the variation in the concentration of the added water: (a) $0 \mathrm{M}$, (b) $5.0 \mathrm{M}$, and (c) $20.8 \mathrm{M}$.

The typical XRD profile of the electrodeposited Ag shows only Ag diffraction peaks (Figure 6), indicating that the purity of the deposited Ag is sufficiently high. Table 2 provides a summary of the GDMS results of the Ag recovered from the MSA-based mixtures through electrowinning. The results show that the Ag metal recovered from the solution has purity as high as $\sim 99.92 \%$ (3N2). However, large amounts of sulfur and chloride are present as impurities. Both sulfur and chloride are considered to degrade in MSA due to the high applied current density during the electrolytic recovery process. Sulfur is considered to electrochemically decompose in MSA due to the high applied current density during the electrowinning process. As for chloride, it is considered that MSA electrochemically decomposes from the MSA mixtures used as the electrolyte, and is converted into the corresponding sulfonyl chloride, methanesulfonyl, or mesyl chloride [28]. This outcome is significant in that it not only provides an environmentally friendly process that facilitates the recovery of Ag with high purity, but also demonstrates that the process is applicable to actual EoL PV modules.

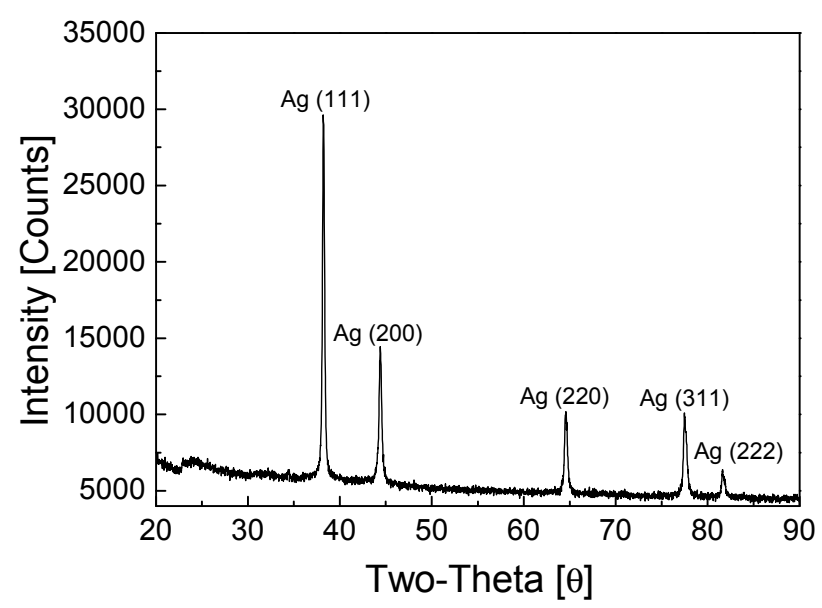

Figure 6. X-ray diffraction profile of deposited Ag. 
Table 2. Purity of the as-recovered Ag powder.

\begin{tabular}{cccc}
\hline Elements & Concentration (ppmw) & Elements & Concentration (ppmw) \\
\hline $\mathrm{Li}$ & $<0.005$ & $\mathrm{Cr}$ & 1.5 \\
$\mathrm{Be}$ & $<0.001$ & $\mathrm{Mn}$ & 0.09 \\
$\mathrm{~B}$ & $<0.005$ & $\mathrm{Fe}$ & 5.4 \\
$\mathrm{Na}$ & 0.45 & $\mathrm{Co}$ & 0.006 \\
$\mathrm{Mg}$ & 0.06 & $\mathrm{Ni}$ & 0.87 \\
$\mathrm{Al}$ & 0.98 & $\mathrm{Cu}$ & 0.11 \\
$\mathrm{Si}$ & 2.9 & $\mathrm{Zn}$ & 0.03 \\
$\mathrm{P}$ & 5.8 & $\mathrm{Ga}$ & $<0.1$ \\
$\mathrm{~S}$ & 220 & $\mathrm{Ge}$ & $<0.1$ \\
$\mathrm{Cl}$ & $\mathrm{Ag}$ & $\mathrm{Matrix}$ \\
$\mathrm{K}$ & $\sim 600$ & $\mathrm{Sn}$ & 12 \\
$\mathrm{Ca}$ & 0.16 & $\mathrm{~Pb}$ & $<0.05$ \\
$\mathrm{Ti}$ & 0.19 & $\mathrm{Bi}$ & 0.02 \\
\hline
\end{tabular}

\section{Conclusions}

The recovery of Ag from c-Si solar cells using MSA, rather than inorganic acids, is advantageous from an environmental point of view, as MSA does not give rise to typical problems associated with the generation of waste acid solutions and toxic fumes. Furthermore, it has a remarkably high solubility for Ag and high thermal stability; however, the mobility of Ag ions is not high in MSA owing to its high viscosity and, consequently, the electrochemical efficiency is low. Increasing the concentration of water added to the mixed solution decreased the viscosity of the solution which, in turn, increased the mobility of the Ag ions in the mixed solution. The increased mobility of Ag ions in the mixed solution resulted in an increase in the cathode efficiency. As a result, the optimal concentration of the added water is found to be $20.8 \mathrm{M}$. The purity of the Ag recovered from the mixed solution was found to be $99.9 \%(9 \mathrm{~N})$ with a low concentration of impurities, such as sulfur and chloride. The feasibility of this method was confirmed by the successful processing of c-Si solar cells.

Author Contributions: Conceptualization, J.-K.L. and J.-S.L.; formal analysis, J.-K.L.; investigation, J.-K.L. and J.-S.L.; writing —original draft preparation, J.-K.L.; writing—review and editing, J.-S.L. and Y.-S.A. and G.-H.K.; funding acquisition, J.-S.L.

Funding: This research was funded by the Korea Institute of Energy Technology Evaluation and Planning (KETEP) and by the Ministry of Trade, Industry \& Energy (MOTIE) of the Republic of Korea (No. 20163010012240, 20163010012230).

Acknowledgments: This work was supported by the Korea Institute of Energy Technology Evaluation and Planning (KETEP) and by the Ministry of Trade, Industry \& Energy (MOTIE) of the Republic of Korea (No. 20163010012240, 20163010012230).

Conflicts of Interest: The authors declare no conflict of interest.

\section{References}

1. Tao, J.; Yu, S. Review on feasible recycling pathways and technologies of solar photovoltaic modules. Sol. Energy Mater. Sol. Cells 2015, 141, 108-124. [CrossRef]

2. Doi, T.; Tsuda, I.; Unagida, H.; Murata, A.; Sakuta, K.; Kurokawa, K. Experimental study on PV module recycling with organic solvent method. Sol. Energy Mater. Sol. Cells 2001, 67, 397-403. [CrossRef]

3. Granata, G.; Pagnanelli, F.; Moscardini, E.; Havlik, T.; Toro, L. Recycling of photovoltaic panels by physical operations. Sol. Energy Mater. Sol. Cells 2014, 123, 239-248. [CrossRef]

4. Directive, E.C. Directive 2012/19/EU of the European Parliament and of the Council of 4 July 2012 on waste electrical and electronic equipment, WEEE. Off. J. Eur. Union L 2012, 197, 38-71.

5. Weckend, S.; Wade, A.; Heath, G. End-of-Life Management: Solar Photovoltaic Panels; No. NREL/BK6A20-66178; National Renewable Energy Lab. (NREL): Golden, CO, USA, 2016.

6. Nieland, S.; Neuhaus, U.; Pfaff, T.; Radlein, E. New approaches for component recycling of crystalline solar modules. In Proceedings of the Electronics Goes Green 2012+(EGG), Berlin, Germany, 9-12 September 2012; pp. 1-5. 
7. Palitzsch, W.; Loser, U. A new and intelligent de-metalization step of broken silicon cells and silicon cell production waste in the recycling procedure of crystalline Si modules. In Proceedings of the 37th IEEE Photovoltaic Specialists Conference (PVSC), Seattle, WA, USA, 19-24 June 2011.

8. Dias, P.; Javimczik, S.; Benevit, M.; Veit, H.; Bernardes, A.M. Recycling WEEE: Extraction and concentration of silver from waste crystalline silicon photovoltaic modules. Waste Manag. 2016, 57, 220-225. [CrossRef] [PubMed]

9. Yi, Y.K.; Kim, H.S.; Tran, T.; Hong, S.K.; Kim, M.J. Recovering valuable metals from recycled photovoltaic modules. J. Air Waste Manag. Assoc. 2014, 64, 797-807. [CrossRef] [PubMed]

10. Lee, J.K.; Lee, J.S.; Ahn, Y.S.; Kang, G.H. Effect of current density on morphology of silver thin film recovered from crystalline silicon solar cell by electrochemical process. Thin Solid Films 2018, 663, 143-147. [CrossRef]

11. Klugmann-Radziemska, E. Recycling of Photovoltaic Solar Cells and Modules-The State-Of-Art; Lambert Academic Publishing: Saarbrücken, Germany, 2014; pp. 1-53. ISBN 978-3-659-51951-2.

12. Lee, C.H.; Hung, C.E.; Tsai, S.L.; Popuri, S.R.; Liao, C.H. Resource recovery of scrap silicon solar battery cell. Waste Manag. Res. 2013, 31, 518-524. [CrossRef] [PubMed]

13. Kuczyńska-Łażewska, A.; Klugmann-Radziemska, E.; Sobczak, Z.; Klimczuk, T. Recovery of silver metallization from damaged silicon cells. Sol. Energy Mater. Sol. Cells 2018, 176, 190-195. [CrossRef]

14. Hiskey, J.B.; Sanchez, V.M. Mechanistic and kinetic aspects of silver dissolution in cyanide solutions. J. Appl. Electrochem. 1990, 20, 479-487. [CrossRef]

15. Huang, W.H.; Shin, W.J.; Wang, L.; Sun, W.C.; Tao, M. Strategy and technology to recycle wafer-silicon solar modules. Sol. Energy 2017, 144, 22-31. [CrossRef]

16. Yang, E.H.; Lee, J.K.; Lee, J.S.; Ahn, Y.S.; Kang, G.H.; Cho, C.H. Environmentally friendly recovery of Ag from end-of-life c-Si solar cell using organic acid and its electrochemical purification. Hydrometallurgy 2017, 167, 129-133. [CrossRef]

17. Gernon, M.D.; Wu, M.; Buszta, T.; Janney, P. Environmental benefits of methanesulfonic acid. Comparative properties and advantages. Green Chem. 1999, 1, 127-140. [CrossRef]

18. Suo, L.; Hu, Y.S.; Li, H.; Armand, M.; Chen, L. A new class of solvent-in-salt electrolyte for high-energy rechargeable metallic lithium batteries. Nat. Commun. 2013, 4, 1481. [CrossRef] [PubMed]

19. Seki, S.; Hayamizu, K.; Tsuzuki, S.; Takahashi, K.; Ishino, Y.; Kato, M.; Nozaki, E.; Watanabe, H.; Umebayashi, Y. Density, viscosity, ionic conductivity, and self-diffusion coefficient of organic liquid electrolytes: Part I. Propylene carbonate $+\mathrm{Li}, \mathrm{Na}, \mathrm{Mg}$ and Ca cation salts. J. Electrochem. Soc. 2018, 165, A542-A546. [CrossRef]

20. Bandara, T.M.W.J.; Mellander, B.E. Evaluation of mobility, diffusion coefficient and density of charge carriers in ionic liquids and novel electrolytes based on a new model for dielectric response. In Ionic Liquids: Theory, Properties, New Approaches; InTech: London, UK, 2011; pp. 383-406. ISBN 978-953-307-349-1.

21. Neghmouche, N.S.; Lanez, T. Calculation of electrochemical parameters starting from the polarization curves of ferrocene at glassy carbon electrode. Int. Lett. Chem. Phys. Astron. 2013, 4, 37-45. [CrossRef]

22. Edward, J.T. Molecular volumes and the Stokes-Einstein equation. J. Chem. Educ. 1970, 47, 261. [CrossRef]

23. Hazza, A.; Pletcher, D.; Wills, R. A novel flow battery: A lead acid battery based on an electrolyte with soluble lead (II) Part I. Preliminary studies. Phys. Chem. Chem. Phys. 2014, 6, 1773-1778. [CrossRef]

24. Stankovic, V. Metal removal from effluents by electrowinning and a new design concept in wastewater purification technology. Chem. Biochem. Eng. Q. 2007, 21, 33-45.

25. Rahman, H.A.; Moustafa, A.H.E.; Magid, S.A. High rate copper electrodeposition in the presence of inorganic salts. Int. J. Electrochem. Sci. 2012, 7, 6959-6975.

26. Wang, K.; Pei, P.; Ma, Z.; Chen, H.; Xu, H.; Chen, D.; Wang, X. Dendrite growth in the recharging process of zinc-air batteries. J. Mater. Chem. A 2015, 3, 22648-22655. [CrossRef]

27. Borikar, D.K.; Umare, S.S.; Viswanath, S.G. Electrowinning of Nickel from ammonical sulphate bath and effect of acetone on morphology of nickel deposit and its correlation with kinetic parameters. Metalurgija 2005, 45, 3-8.

28. Szmant, H.H. Organic Building Blocks of the Chemical Industry; John Wiley \& Sons: New York, NY, USA, 1989; p. 92. ISBN 0-471-85545-6.

(C) 2018 by the authors. Licensee MDPI, Basel, Switzerland. This article is an open access article distributed under the terms and conditions of the Creative Commons Attribution (CC BY) license (http:/ / creativecommons.org/licenses/by/4.0/). 